\section{Conflicts Involving Brown Bear and Other Large Carnivores in the Kalam Valley, Swat, Pakistan}

\author{
Arshad Ali ${ }^{1}$, Muhammad Nasir Khan Khattak ${ }^{2 *}$, Muhammad Ali Nawaz ${ }^{3}$ and \\ Shoaib Hameed ${ }^{3}$ \\ ${ }^{1}$ Department of Zoology, Hazaara University, Mansehra \\ ${ }^{2}$ Department of Applied Biology, College of Sciences, University of Sharjah, United \\ Arab Emirates \\ ${ }^{3}$ Department of Animal Sciences, Quaid-i-Azam University, Islamabad
}

\begin{abstract}
A B S T R A C T
Humans living close to carnivore habitats sometimes develop a negative attitude towards them because of the damages they cause. Such an attitude has costs, both for wild carnivores and local communities. Human costs are mostly in the form of economic loss to property and infrastructure, damage to crops, and depredation on livestock. In northern Pakistan where large carnivores like common leopard (Panthera pardus), snow leopard (Panthera uncia), Asiatic black bear (Ursus thibetinus), Himalayan brown bear (Ursus arctos isabellinus)), grey wolf (Canis lupus), and lynx (Lynx lynx) often encounter humans and contribute to significant economic losses. The present study was conducted in Kalam Valley, District Swat, Pakistan to estimate the occurrence of brown bear and conflicts with humans. Data about the presence-absence and depredation in five years (2009-2013) were collected from 86 households in the area. Total losses in Kalam Valley during the five year period were 72 animals. The brown bear predation was estimated as $29 \%$ of total predation in the area that killed 15 goats, 2 sheep, and 4 cattle. The snow leopard and wolf predation was $31 \%$ and $39 \%$, respectively. To estimate the occurrence, 10 transects were laid out in each survey area with $100 \mathrm{~m}$ length and $50 \mathrm{~m}$ width. Each transect was laid out with minimum distance of one $\mathrm{km}$ from each other. Higher sign density was found in the forest compared to the other habitats. Twenty brown bear signs were recorded at four sites of the study area. According to signs, brown bear was widely distributed in Batendar area, while Jaba had the least distribution. Estimated livestock predation per household was $0.84 \pm 1.13$ animals. The total economic loss was PKR 20,207 or US\$ 196 per household/year. The economic loss due to brown bear was PKR 5860 or US\$ 58, snow leopard as PKR 6264 or US\$ 63 and wolf as PKR 7880 or US\$ 78 per household/year. Livestock predation and crop damages resulted in ruthless killing of large carnivores including brown bear in the area, which makes conservation efforts difficult.
\end{abstract}

\begin{tabular}{l} 
Article Information \\
\hline Received 04 June 2020 \\
Revised 02 July 2020 \\
Accepted 07 July 2020 \\
Available online 30 July 2021 \\
Authors' Contribution \\
\hline MNKK and MAN designed the \\
study and questionnaire. AA and SH \\
performed the fieldwork. MNK, MAN \\
analysed the data. AA wrote the first \\
draft. MNKK, MAN and SH revised \\
and finalized the drafts. \\
Key words \\
\hline Large carnivores, Conflict, \\
Distribution, Conservation, Kalam
\end{tabular}

\section{INTRODUCTION}

$\mathrm{H}^{2}$ umans living close to carnivore habitats sometimes develop a negative attitude towards them, because of damages they cause, thus causing conservation challenges (Woodroffe et al., 2005). Large carnivores are more disposed to such conflicts, as they often attack the livestock (Treves and Karanth, 2003).

Human-carnivore conflicts have costs, both for wild carnivores and local communities. Human costs are mostly in the form of economic loss to property and infrastructure, damage to crops, and depredation on livestock. Humancarnivore conflicts have large and unequal effects on rural

\footnotetext{
* Corresponding author: mnasir43663@gmail.com, mnasir@sharjah.ac.ae 0030-9923/2021/0005-1889 \$ 9.00/0

Copyright 2021 Zoological Society of Pakistan
}

communities, because people living near carnivores tend to belong to the lowest income categories. As a result, rural people often have low tolerance towards carnivores, their conservation, and the conservation of other non-conflict species. Humans often incorrectly identify offenders that cause the most losses (Linkie et al., 2007). Sometimes, large carnivores also attack humans, causing injuries or even death (White and Gehrt, 2009) that may lead to poisoning or shooting of the carnivores by humans (Frank et al., 2005).

There are only a few studies on human-carnivore conflicts in Pakistan (Dar et al., 2009; Din and Nawaz, 2010; Bibi et al., 2013; Hameed et al., 2013; Perveen and Abid, 2013; Kabir et al., 2014), although these conflicts are widespread. This is particularly the case in northern Pakistan, where common leopard, snow leopard, Asiatic black bear, Himalayan brown, grey wolf, and Eurasian lynx often cause significant economic losses. We designed 
this study to document the occurrence of large carnivores in Kalam Valley of Swat, Khyber Pakhtunkhwa, northern Pakistan, and to estimate the magnitude of economic damages they cause to the humans living in the valley.

\section{MATERIALS AND METHODS}

\section{Study area}

Our study was conducted in the Kalam valley, District Swat, northern Pakistan (Fig. 1). Swat is a mountainous green valley, which lies between $34^{\circ}-40^{\circ}$ to $35^{\prime} \mathrm{N}$ latitude and $72^{\circ}-74^{\circ}$ to $60^{\prime} \mathrm{E}$ longitude with elevation ranging between 2000 and 3900 meters above sea level. It is located approximately $160 \mathrm{~km}$ north of Islamabad, the capital city of Pakistan. The total area of Kalam Valley is approximately $1600 \mathrm{~km}^{2}$. The highest temperature in July is $38^{\circ} \mathrm{C}$ and lowest during January is $-4^{\circ} \mathrm{C}$.. Kalam is a spacious subvalley of Swat. It is located at a distance of 99 kilometers (62 miles) from Mingora in the upper reaches of Swat valley along the River Swat. Kalam is known for its lakes, waterfalls, and lush green hills and is a popular destination

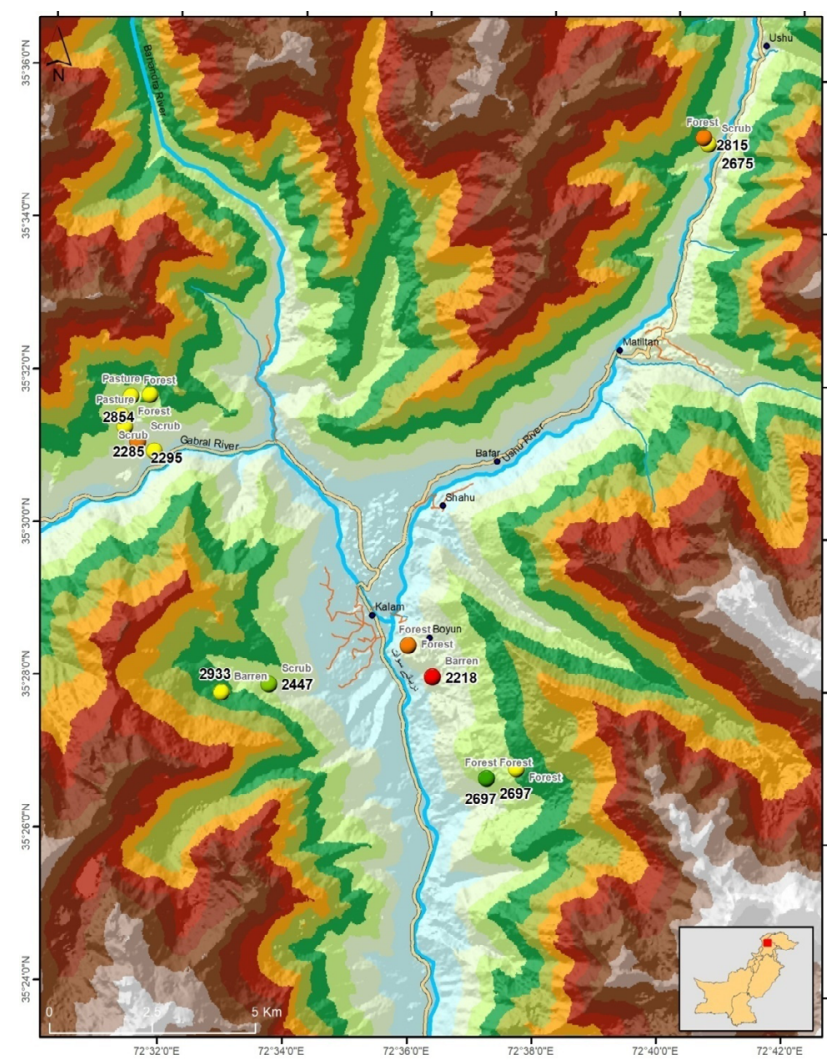

Fig. 1. Map of the study area (Kalam Valley, Swat District, Pakistan). The inlaid map shows the location, habitat type and elevation of the large carnivore signs found in each site of the study area. for tourists. The climate is harsh during winter (November, December, January, February) with frequent snowfall and moderate during summer (June, July, August) Rain is frequent in March and April, but summer (June-August) and autumn (September and October) are relatively dry seasons (Hamayun et al., 2006).

About $160 \mathrm{~km}^{2}$ forest is dominated by silver fir (Abies pindrow), spruce (Picea smithiana), deodar (Cedrus deodara) and kail or blue pine (Pinus wallichiana) (Stucki and Khan, 1999). The broken mountains with steep terrain support populations of mountain ungulate species, like Kashmir markhor (Capra falconeri cashmiriensis) and Himalayan ibex (Capra ibex sibirica). The valley provides habitat to a variety of wildlife, including musk deer (Moschus chrysogaster), markhor, and Rhesus monkey (Macaca mulatta) among mammals and phasianids like monal pheasant (Lophophorus impejanus), Koklass pheasant (Pucrasia macrolopha), snow cock (Tetraogallus himalayensis), chukor partridge (Alectoris chukar), and see see partridge (Ammoperdix griseogularis), and a variety of small songbirds (Ahmad et al., 2004).

\section{Study species}

Most of the large carnivores in Northern Pakistan do not have a favorable conservation status. Their habitats are being reduced and local people often persecute them. The Himalayan brown bear occurs in small populations in Pakistan and is listed in Appendix 1 of CITES (Convention on International Trade in Endangered Species of Wild Fauna and Flora). Historically, it occurred in the Western Himalayas, Karakoram, Hindu Kush, Pamir, Western Kulan Shan, and Tian Shan ranges (Nawaz, 2007). The common leopard is the most widely distributed of all the cat species in the world. It is found in every kind of habitat ranging from the rain forests to tropics to deserts and temperate regions. Leopards face several threats to their survival, including direct poaching, diminishing prey base, habitat fragmentation and habitat degradation. It is classified as a vulnerable species in the IUCN Red Data List (IUCN, 2020). It serves as a flagship species in several protected areas of Pakistan. In several protected areas of Pakistan, it occurs throughout the northern mountain ranges (Malik, 1997), with an estimated population of 100-450 in an area of approximately $80,000 \mathrm{~km}^{2}$ making the overall habitat of this species in Pakistan where half of it is considered to be the primary habitat (Malik, 1997).

The grey wolf is distributed throughout Pakistan (Roberts, 1997) and is listed as an endangered species in the Red List of Pakistan mammals (Sheikh and Molur, 2005). Globally, it is considered as a least concerned species (IUCN, 2020). The Eurasian lynx is listed as near threatened (NT 3.1) in the IUCN Red List (Global: 
Category 5b. Regional (Asia): Category 3).

\section{Study design}

The study comprised of two parts i.e. the occurrence of large carnivores in the region and conflicts with humans.

\section{Occurrence of large carnivores}

We conducted a field survey in four areas of Kalam Valley in September-October 2014 to document the occurrence of large carnivores. We divided the area into four major sites namely Batender, Desan valley, Shateer and Jaba. Transects were plotted in randomly selected feasible landforms where large carnivore signs were likely to be found, such as ridgelines, cliff bases, river bluffs, saddle, and forest. We placed 10 equidistant transects (one $\mathrm{km}$ ) in each area with $100 \mathrm{~m}$ length and $50 \mathrm{~m}$ width. At the starting point of each transect, we recorded GPS position, location, date, observer name and starting point like; Batendar (35.5210 № latitude-72.5211 ${ }^{\circ} \mathrm{E}$ longitude, 2441 meter elevation), Dehsan Valley (35.4748 $\mathrm{N}^{\circ}$ latitude-72.5984 $\mathrm{E}^{\mathrm{o}}$ longitude, 2278 meter elevation), Shateer (35.4462 $\mathrm{N}^{\circ}$ latitude - $72.6203 \mathrm{E}^{\mathrm{o}}$ longitude, 2697 meter elevation), and Jaba (35.4657 $\mathrm{N}^{\circ}$ latitude - $72.5613 \mathrm{E}^{\circ}$ longitude, 2447 meter elevation). Transects were walked slowly, and wherever a sign was found, we recorded its distance from the starting point, site number, kind (track, scrap, and scat) and number of signs, and estimated age. The signs of snow leopard were distinguished from common leopard and lynx using snow leopard survey and conservation handbook (Jackson and Hunter, 1996). In addition, we analyzed data from the regional wildlife department and available published and unpublished information. We visited the four transects regularly 20 times, 10 days in each month between 08:00 $\mathrm{h}-17: 00 \mathrm{~h}$. The habitats of the four transects were forest, pasture, barren and scrub type, with an average elevation range from 2295 to $2854 \mathrm{~m}$ above mean sea level.

\section{Conflict survey}

We selected 86 households for interview based on their interaction with livestock and wild animals i.e. either the livestock owners or illegal hunters of wild animals. The Kalam Valley has around 8000 households in total. The 86 interviewed households belonged to localities like Buyoun, Kass, Kalam main Bazar, Koknail, Chiyar and Jalband. The interviewees were asked about subjective estimates of large carnivores in the area, sightings or other evidence, number of livestock owned and depredations, and a general impression from the local people during the past five years (2008-2013) about human and carnivore conflict. Usually we selected a head of the family or an adult person for interview to collect information about his livestock, depredation of livestock by large carnivores, sighting of carnivores and perception about brown bear and other large carnivores.

We categorized human acceptance of wildlife species into four categories, with four being the highest level of acceptance, and asked about the species' perceived danger. We asked about the livestock owned per household and mortality due to disease in the past five years. We also inquired about crop damages in the area by the large carnivores by season (winter, spring, summer and autumn) of the previous year/s. In case of sighting of any large carnivores, we further confirmed by asking general and specific questions about large carnivores' appearance to avoid bias in the data. Geographical information system (GIS) ArcMap10 was used to develop maps. We used the Mean \pm Standard deviation to present the results.

\section{RESULTS}

\section{Occurrence of large carnivore species}

We found 20 signs of five large carnivores on the four transects; 10 of brown bear, three of grey wolf, four of red fox, one of snow leopard and two of lynx (Table I). Three scats and seven tracks of brown bear were recorded at elevation between $2295-2854 \mathrm{~m}$. We also found two scats and two tracks of fox and three tracks of wolf in forest habitat at elevation from 2278 to 2697 $\mathrm{m}$ in Shater and Dhesan valleys. The presence of snow leopard and lynx was recorded by one and two tracks respectively in barren and scrub habitat in Batendar and Jaba valleys at elevations between 2218 and $2247 \mathrm{~m}$ (Table II).

Table I. Relative abundance of carnivores in the Area, during sign survey.

\begin{tabular}{llll}
\hline Species & $\begin{array}{l}\text { Total } \\
\text { signs }\end{array}$ & $\begin{array}{l}\text { Total } \\
\text { point }\end{array}$ & $\begin{array}{l}\text { Relative } \\
\text { abundance }\end{array}$ \\
\hline Brown bear & 10 & 41 & 0.25 \\
Wolf & 3 & 41 & 0.08 \\
Fox & 4 & 41 & 0.10 \\
Snow leopard & 1 & 41 & 0.03 \\
Lynx & 2 & 41 & 0.05 \\
\hline
\end{tabular}

\section{Livestock demography}

Livestock ownership varied where some families owned a large number of livestock heads that were used as a source of bread and butter whereas others kept only a few livestock heads for their family use. Households on an average owned 5.13+6.60 livestock heads comprising an average of $1.95 \pm 2.89$ goats, $1.09 \pm 4.06$ sheep, 1.83 
Table II. Large carnivores sign found in four sites of the study area along with habitat, elevation and GPS coordinates during sign survey.

\begin{tabular}{|c|c|c|c|c|c|c|c|}
\hline Transects name & Habitat & Elevation (m) & Number of individuals & Sign type & Species & Latitude & Longitude \\
\hline Transect no. 1 & Forest & 2441 & 1 & Track & B.bear & 35.52108 & 72.52113 \\
\hline \multirow[t]{6}{*}{ (Batendar) } & Pasture & 2458 & 1 & Track & B.bear & 35.5235 & 72.5201 \\
\hline & Forest & 2854 & 1 & Scat & B.bear & 35.5278 & 72.52252 \\
\hline & Pasture & 2613 & 1 & Scat & B.bear & 35.52821 & 72.5276 \\
\hline & Scrub & 2285 & 1 & Track & B.bear & 35.51595 & 72.52919 \\
\hline & Scrub & 2675 & 1 & Scat & B.bear & 35.58586 & 72.67564 \\
\hline & Scrub & 2295 & 1 & Track & Fox & 35.51788 & 72.52467 \\
\hline Transect no. 2 & Forest & 2278 & 1 & Track & B.bear & 35.47486 & 72.59842 \\
\hline \multirow[t]{3}{*}{ (Dehsan) } & Forest & 2815 & 2 & Scat & Fox & 35.58723 & 72.67428 \\
\hline & Forest & 2278 & 1 & Scat & Wolf & 35.47486 & 72.59842 \\
\hline & Barren & 2218 & 1 & scrap & S.leopard & 35.46816 & 72.60509 \\
\hline Transect no. 3 & Forest & 2697 & 1 & Track & B.bear & 35.44627 & 72.6203 \\
\hline \multirow[t]{4}{*}{ (Shateer) } & Forest & 2821 & 1 & Track & b.bear & 35.44851 & 72.62817 \\
\hline & Barren & 2933 & 1 & Track & b.bear & 35.46365 & 72.54866 \\
\hline & Forest & 2278 & 1 & Track & Fox & 35.47486 & 72.59842 \\
\hline & Forest & 2697 & 2 & Track & Wolf & 35.44627 & 72.6203 \\
\hline $\begin{array}{l}\text { Transect no. } 4 \\
(\mathrm{Jaba})\end{array}$ & Scrub & 2447 & 2 & Track & Lynx & 35.46575 & 72.56134 \\
\hline Total & & & 20 & & & & \\
\hline
\end{tabular}

\pm 1.84 cattle, and $0.26 \pm 0.67$ yaks and other livestock. Using the above average, the total estimated livestock in the valley was 41,023 . Each respondent reported selling an average of $1.22+2.46$ livestock annually, including $0.47 \pm 1.01$ goats, $0.44 \pm 1.57$ sheep, and $0.31 \pm 0.57$ cattle. There was no reported selling of yaks or other livestock. We estimated that the total annual value of sold livestock was PKR 12,767 or US\$125 per household. The people in the communities also slaughtered their livestock for personal consumption. Each household consumed an average of $0.33 \pm 0.69$ livestock per year $(0.10 \pm 0.34$ goats, $0.12 \pm 0.38$ sheep, and $0.11 \pm 0.41$ cattle). The annual value of livestock slaughtered for private consumption per household/year was PKR7,441 or US\$73.

\section{Acceptance of wildlife by humans}

The attitudes of people in the local community towards different carnivores varied by species. The most acceptable species in the area was brown bear $(20 \%)$. The brown bear was considered a dangerous animal both for humans and their livestock, but 20\% acceptance shows that still it was accepted in the environment by a striking percentage of locals. The percentage acceptance of the snow leopard, lynx and wolf were $18 \%, 16 \%$ and $15 \%$, respectively. The wolf was the least favored species, according to local respondents, and around $85 \%$ of the locals wanted to get rid of it from the area.

\section{Conflict and perception of conflicts among locals with} carnivores

The perception of the danger for people posed by the carnivores varied species to species. Lynx was considered dangerous by $37 \%$ of respondents followed by $31 \%$ for wolf, 19\% for brown bear, and $15 \%$ for snow leopard. The highest percentage for lynx was because it caused more damages to pets and birds.

\section{Livestock predation}

A total of 72 cases of depredation, the total loss of 86 households in the valley by three carnivore species (snow leopard, brown bear and wolf) were reported by the respondents in the five year period (2009-2013) in the area including 47 (65\%) goats, 17 (23\%) sheep, 7 (9\%) cattle and $1(2 \%)$ yak. Brown bear reportedly killed $29 \%$ of the total depredated livestock; 15 goats, 2 sheep and 4 cattle. The snow leopard depredation was $31 \%$ that killed 13 goats, 7 
sheep, 1 cattle and 1 yak while wolf depredation was 39\% that killed 20 goats, 7 sheep and 1 cattle. To divide the total depredated livestock (72) by total number of respondent (86) we estimated the total loss due to depredation per household/ year to be $0.84 \pm 1.13$ animals. The economic losses were calculated using local price in 2014 for each livestock in PKR as; 12,255 for goats, 33,878 for sheep, 82,277 for cattle and 10,000 for other animals. The total economic loss was found to be PKR $1,737,850$ or US\$ 16,872 suffered by 86 households/ year. The average economic loss was noted as PKR 20,207 or US\$ 196 per household/ year (Fig. 2).

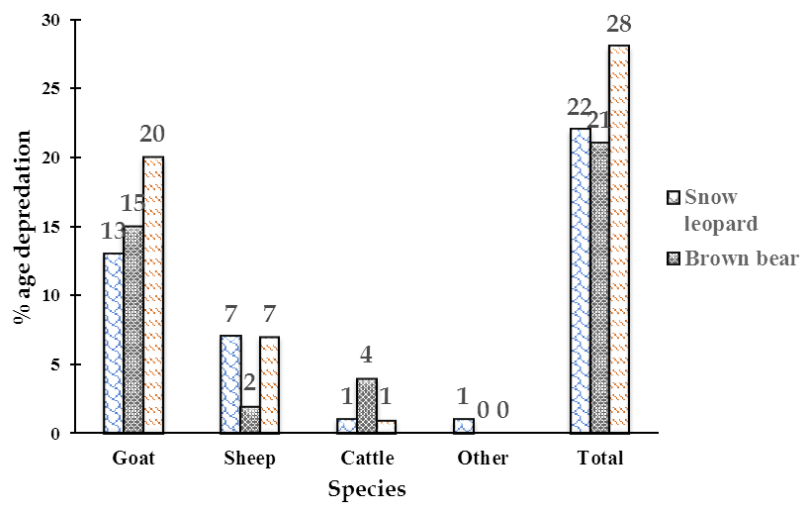

Fig. 2. Depredation of livestock by three carnivore species i.e. snow leopard, brown bear and wolf in Kalam Valley.
Crop damages in the area by wild animals

Maize (corn) was the most often damaged crop by carnivores. Mostly the crops were damaged in winter, summer, and spring seasons by brown bear. Bear-caused damage was also reported for potatoes and apricots. The people claimed that they were losing about two sacks of potatoes $(50 \mathrm{~kg} \mathrm{sac}=2000 \times 86=$ PKR 172,000 or US $\$$ $1687)$ and three crates of apricot $(5 \mathrm{~kg}$ crate $=500 \times 86=$ PKR 4300 or US\$ 422) per household annually. There was no record of crop damages by other carnivores or wild animals. The people told their raw estimation (no real time calculation) of losing about one sack $(10 \mathrm{~kg})$ of maize per household annually $(10 \mathrm{~kg} \mathrm{sack}=1605 \times 86=\mathrm{PKR} 138,036$ or US\$1355) by 86 households in the valley (Table III).

\section{Human attacks and cub poaching}

Four attacks were reported on humans by carnivores i.e. two brown bear, one snow leopard and one wolf. Unfortunately, one of these at Batendar by brown bear didn't survive the injuries. The other three sustained major injuries. Only three cases of bear poaching were reported, (one bear cub from Shateer and two from Jaba). The respondent also reported the killing of one brown bear and one snow leopard in the previous year (Table III).

\section{Livestock mortality due to diseases}

The average reported number of livestock deaths due to diseases per household /year was $3.38 \pm 9.30$ animals; $1.71 \pm 5.66$ goats, $0.83 \pm 3.58$ sheep, $0.79 \pm 1.16$ cattle and

Table III. Human carnivores conflict and season wise crop damages by large carnivores at four sites of the area.

\begin{tabular}{|c|c|c|c|c|c|}
\hline Locality & Species & Crop damage & Season & Man attack & Carnivores killed/Poached \\
\hline \multirow[t]{4}{*}{ Batendar } & B. bear & Maize & winter & Killed & - \\
\hline & S. leopard & - & - & - & - \\
\hline & Wolf & - & - & - & Killed \\
\hline & Lynx & - & - & - & Killed \\
\hline \multirow[t]{4}{*}{ Dhesan } & B. bear & Potato/apricot & Spring & Attack & - \\
\hline & S. leopard & - & - & - & - \\
\hline & Wolf & - & - & - & - \\
\hline & Lynx & - & - & - & Killed \\
\hline \multirow[t]{4}{*}{ Shater } & B. bear & Apricot & Summer & - & Poached \\
\hline & S. leopard & - & - & - & - \\
\hline & Wolf & - & - & - & Killed \\
\hline & Lynx & - & - & - & Killed \\
\hline \multirow[t]{4}{*}{ Jaba } & B. bear & Maize & Winter & - & Mother + Cub \\
\hline & S. leopard & - & - & Attack & Killed \\
\hline & Wolf & - & - & Attack & Killed \\
\hline & Lynx & - & - & - & - \\
\hline
\end{tabular}


0.080.38 yak. Based on this, we calculated the total annual loss per household of livestock due to disease to be PKR 27,070 or US\$ 207 /year.

The average reported income from selling the livestock per household per year was PKR 12,767 or US\$ 125.

\section{DISCUSSION}

Along our transects, we documented signs of four species of large carnivores (Table I) that were reported to be in the area by the respondents viz., snow leopard, brown bear, lynx, and wolf. Livestock owned per household on an average of 86 households was $5.13 \pm 6.60$. We estimated the total livestock population as 41,023 in the valley, with an average selling of $1.22 \pm 2.46$ ) livestock annually. The total income value of sold livestock was noted as PKR 12,767 or US\$125.2. The livestock slaughtered for personal consumption was calculated as $0.33 \pm 0.69$ per household per year, that equates PKR7441 or US\$ 73. The average number of livestock deaths due to diseases per household /year was $3.38 \pm 9.30$ animals. The total annual loss to livestock diseases per household /year was PKR 27,070 or US\$ 207. The high risk of mortality in livestock from diseases was due to non-availability of vaccination and medication.

The average mortality of livestock due to diseases was more than the number of livestock sold per household per year in the area. The livestock rearing and agriculture are the main source of the economy. The economic loss caused by the mortality of livestock due to disease per household (207 US\$) is to be considered a small amount. However, in Pakistan or in such remote areas the mortality of even a small number of livestock is considered a huge economic loss, as the overall monthly income of the locals per month was not more than 100 US\$. Hence, the carnivore attack on livestock and mortality due to diseases collectively caused a very huge economic loss. As the locals are unaware of the importance of biodiversity and hence don't tolerate even small losses.

Conflicts and perceptions varied by species. The lynx was considered very dangerous by local respondents whereas the wolf and the brown bear were considered less dangerous and snow leopard was considered to be the least dangerous species in the area. The contributing factor for low perception about snow leopard was due to low depredation of livestock and no crop damages in the area.

The calculated economic loss per household peryear due to depredation of livestock by large carnivores i.e. snow leopard, brown bear, wolf and lynx was PKR 20,207 or US\$ 196 is lower than the predation loss reported from other parts of Pakistan. The predation losses reported from other area such as Torkhow valley, Chitral are 276 livestock per year with economic losses of 28,145 US\$(US\$ 189 per household) (Din and Nawaz, 2010), Machiara National Park 99 (Dar et al., 2009), Dhirkot, Azad Jammu and Kashmir 216 (Bibi et al., 2013), and Hindu Kush Mountain 261 (Din et al. 2013). Corresponding figures for India are 57 (Ahmed et al., 2012) and 23 (Singh et al., 2015). In China, reported numbers are 258 (Li et al., 2013) and 76 for Bhutan (Wang and Macdonald, 2006). Such losses, when combined with restrictions on the use of natural resources, are likely to generate aggressive attitudes towards conservation and may provoke retaliatory action by farmers (Conforti et al., 2003).

The reason for low depredation of livestock in the area might be the extreme care of their livestock by nomadic people. Migration of nomads along with their livestock in the very harsh climate also reduces the chances of depredation.

Human-carnivore conflict is a global problem (Apker, 2003) and is associated with increasing human population (Baruch-Mordo et al., 2008). One of the main reasons for human-carnivore conflict in the world is the killing of livestock by mammalian carnivores (Distefano, 2005). Increased livestock depredation by large carnivores in Pakistan might be attributed to increasing population of livestock (Jackson and Hunter, 1996; Mishra, 1997; Hussain, 2003).

The local respondents blamed brown bear for crop damages leading to economic loss of (USD 1355) of 86 household/per year. Bears raided standing maize crop, and stored grasses and fodder; as the local cut and store grasses and fodder in late summer, causing a major drop for natural food available to bear. The nomads' excessive livestock grazing in rangelands and forested areas during summer also affect food availability for bears. Naeem et al. (2016) reported 108 cases of crop damage by Asiatic black bear. Mean number of crop damages per respondent was 1.02 , with $29 \%$ of respondents suffering a single damage to their crops during the study period. Most crop damages by Asiatic black bears were during the summer (38\%) and autumn (60\%). The annual number of crops damaged increased from 4 and 9 in 2008 and 2009 to 25 and 48 in 2011 and 2012 respectively. Crop damage by carnivores occur in areas that are very close $(<250 \mathrm{~m})$ to the forest edge.

Although carnivores attack humans rarely. However, in the last five years, four attacks were reported. Such attacks, although rare, but cause fear and anger in locals against carnivores. Locals are avoiding such attacks by reducing solitary and late night movements. 


\section{CONCLUSION}

The carnivore attacks on livestock are common and local people have become used to this conflict and have developed certain necessary measures to minimize the risk such as effective nocturnal livestock management and herding during daytime. Livestock predation by carnivores and crop damages by bears have resulted in the ruthless killing of carnivores by the locals and shepherds. Seven killings of large carnivores i.e. 3 wolves, 3 lynx and one snow leopard have been reported in the previous five years. This is the major issue faced by conservationists in the area.

\section{ACKNOWLEDGMENT}

We acknowledge the support of Snow Leopard Foundation (SLF) and Khyber Pakhtunkhwa Wildlife department for the study.

Statement of conflict of interest

The authors have declared no conflict of interest.

\section{REFERENCES}

Ahmad, R.A., Prusty, K., Jena, J., Dave, C., Sunit, K.R.D., Hemanta, K.S. and Ahmad, K., 2004. Final report on snow leopard occurrence in Mankial Valley, Swat. International Snow Leopard Trust Islamabad, Pakistan. pp. 11.

Ahmed, R.A., Prusty, K., Jena, J., Dave, C., Das, S.K., Sahu, H.K. and Rout, S.D., 2012. Prevailing human carnivore conflict in Kanha-Achanakmar corridor, Central India. World J. Zool., 7: 158-164.

Apker, J.A., 2003. Colorado status report. Western Black Bear Management Workshop. pp. 14-20.

Baruch-Mordo, S., Breck, W., Wilson, K.R. and Theobald, D.M., 2008. Spatiotemporal distribution of black bear-human conflicts in Colorado, USA. J. Wildl. Manage. 72: 1853-1862. https://doi. org/10.2193/2007-442

Bibi, S.S., Minhas, R.A., Awan, M.A., Ali, U. and Darn, I., 2013. Study of ethno-carnivore relationship in Dhirkot, Azad Jammu and Kashmir. J. Anim. Pl. Sci., 23: 854-859.

Conforti, V.A. and De Azevedo, F.C.C., 2003. Local perceptions of jaguars (Panthera onca) and pumas (Puma concolor) in the Iguacu National Park area, south Brazil. Biol. Conserv., 111: 215-221. https:// doi.org/10.1016/S0006-3207(02)00277-X

Dar, N.I., Minhas, R.A., Zaman, Q. and Linkie, M., 2009. Predicting the patterns, Perceptions and causes of human-carnivore conflict in and around Machiara National Park, Pakistan. Biol. Conserv., 10: 20762082. https://doi.org/10.1016/j.biocon.2009.04.003

Din, J.U., Hameed, S., Shah, K.A., Khan, M.A., Khan, S., Ali, M. and Nawaz, M.A., 2013. Abundance of canids and human canid conflict in the Hindu Kush Mountain range of Pakistan. Wildl. Biol. Pract., 9: 20-29. https://doi.org/10.2461/wbp.2013.9.5

Din. J., and Nawaz, M.A., 2010. Status of the Himalayan lynx in district Chitral, NWFP, Pakistan. J. Anim. Pl. Sci., 20: 17-22.

Distefano, E., 2005. Human-wildlife conflict worldwide: a collection of case studies, analysis of management strategies and good practices. FAO, Rome, pp. 34.

Frank, K.T, Petrie, B., Choi, J.S. and Legget, W.C., 2005. Tropic cascades in a formerlycod-dominated ecosystem. Science, 308: 1621-1623. https://doi. org/10.1126/science. 1113075

Hamayun, M., Afzal, S. and Khan, M.A., 2006. Ethnopharmacology, indigenous collection and preservation techniques of some frequently used medicinal plants of Utror and Gabral, District Swat, Pakistan. Afr. J. Tradit. Complement. Altern. Med., 3: 10-4314. https://doi.org/10.4314/ajtcam. v3i2.31158

Hussain, S., 2003. The status of the snow leopard in Pakistan and its conflict with local farmers. Oryx, 37: 26-33. https://doi.org/10.1017/ S0030605303000085

Hameed, S., Abbas, K., Younas, M., Murtaza, G., Mahdi, G. and Nawaz, M.A., 2013. Himalayan brown bear in Deosai National Park: Current status and threats. Snow Leopard Foundation, Islamabad.

IUCN, 2020. IUCN red list of threatened species. https:// www.iucnredlist.org/species/22732/50664030 (Accessed on 21st January 2020)

Jackson, R.M. and Hunterd. O., 1996. Snow leopard survey and conservation handbook. International Snow Leopard Trust.

Kabir, M., Ghoddousi, A., Awan, M.S. and Awanm, N., 2014. Assessment of human leopard conflict in Machiara National Park, Azad Jammu and Kashmir, Pakistan. Eur. J. Wildl. Res., 60: 291-296. https:// doi.org/10.1007/s10344-013-0782-Z

Li, J., Yin, H., Wang, D., Jiangong, Z. and Lu, Z., 2013. Human-snow leopard conflict in the Sanjiangyuan region of Tibetan Plateau. Biol. Conserv., 166: 118123. https://doi.org/10.1016/j.biocon.2013.06.024

Linkie, M.Y., Dinata, Y., Nofrianto, A. and LeaderWilliam, N., 2007. Patterns and perceptions ofwildlife crop raiding in and around Kerinci Seblat National Park, Sumatra. Anim. Conserv., 
10: $\quad 127-135 . \quad$ https://doi.org/10.1111/j.14691795.2006.00083.x

Mishra, C., 1997. Livestock depredation by large carnivores in the Indian trans- Himalaya: conflict perception and conservation prospects. Cambridge University Press, Cambridge, UK. https://doi. org/10.1017/S0376892997000441

Malik, M., 1997. Status and conservation of snow leopard in Pakistan. In Proceedings of the Eighth International Snow Leopard Symposium. eds R. Jackson and A. Ahmed, International Snow Leopard Trust, Seattle, USA. pp. 11-20.

Naeem, A.M., Karamanlidis, A.A., Siddique, A.M., Ali, N.M. and Kabir, M., 2016. Prelimenary survey on Asiatic black bear in Kashmir Himalaya, Pakistan: Implictaions for preservation. Int. J. Cons. Sci., 7: 719-724.

Nawaz, A., 2007. Status of the brown bear in Pakistan. Ursus, 18: 89-100. https://doi.org/10.2192/15376176(2007)18[89:SOTBBI]2.0.CO;2

Perveen, F. and Abid, M., 2013. Asian black bear, Ursusthibetanus: humanbear conflict in the Palas Valley, Kohistan, Pakistan. Int. J. Farm. Allied Sci., 2: 1172-1178.

Roberts, T.J., 1997. The mammals of Pakistan. Oxford University Press. New York.

Sheikh, K.M. and Molur, S., 2005. Status and red list of
Pakistan's mammals based on the Pakistan mammal conservation assessment and management plan workshop. IUCN Pakistan, Islamabad, pp. 312.

Singh, R., Nigam, P., Qureshi, Q., Sankar, K., Krausman, P.R., Goyal, S.P. and Nicholoson, K.L., 2015. Characterizing human-tiger conflict in and around Ranthambhore Tiger Reserve, western India. Eur. J. Wildl. Res., 61: 255-261.

Stucki, B. and Khan, H.A., 1999. Working plan for Utror-Desan forests of Kalam Forest Division. Nizam Printing Press, Peshawar.

Treves, A. and Karanth, K.U., 2003. Human-carnivore conflict and perspectives on carnivore management worldwide. Biol. Conserv., 17: 1491-1499. https:// doi.org/10.1111/j.1523-1739.2003.00059.x

Wang, S.W. and Macdonald, D.W., 2006. Livestock predation by carnivores in Jigme Singye Wang chuck National Park, Bhutan. Biol. Conserv. 129: $558-565$. https://doi.org/10.1016/j. biocon.2005.11.024

White, L. and Gehrt, S., 2009. Coyote attacks on humans in the United States and Canada. Hum. Dimen. Wildl., 14: 10-1080. https://doi. org/10.1080/10871200903055326

Woodroffe, R., Thirgood, S. and Rabinowitz, A., 2005. People and wildlife, conflict or co-existence? Cambridge University Press, Cambridge. 